\title{
Metabolic syndrome is associated with advanced prostate cancer in patients treated with radical retropubic prostatectomy: results from a multicentre prospective study
}

Cosimo De Nunzio ${ }^{1 *}$, Giuseppe Simone ${ }^{2,3}$, Aldo Brassetti ${ }^{1}$, Riccardo Mastroianni ${ }^{2}$, Devis Collura ${ }^{2,3}$, Giovanni Muto ${ }^{2,3}$, Michele Gallucci ${ }^{2}$ and Andrea Tubaro ${ }^{1}$

\begin{abstract}
Background: Prostate cancer (PCa) is the most common non-skin cancer in USA and the second leading cause of cancer death in Western Countries. Despite the high mortality associated with PCa, the only established risk factors are age, race and family history. A possible association between metabolic syndrome (MetS) and PCa was firstly described in 2004 and several subsequent studies in biopsy cohorts have shown conflicting results. Aim of our multicentre prospective study was to investigate the association between MetS and PCa in men undergoing radical prostatectomy (RP).

Methods: From January 2012 to June 2015, 349 consecutive men undergoing RP for PCa at three centres in Italy were enrolled into a prospective database. Body Mass Index (BMI) as well as waist circumference was measured before RP. Blood samples were also collected and tested for total PSA, fasting glucose, triglycerides and HDLs. Blood pressure was also recorded. We evaluated the association between MetS, defined according to Adult Treatment Panel III, PCa stage (advanced stage defined as $\mathrm{pT} \geq 3$ or N1) and grade (high grade defined as Gleason Score $\geq 4+3)$ using logistic regression analyses.

Results: Median age and preoperative PSA levels were 66 years (IQR: 61-69) and $7 \mathrm{ng} / \mathrm{ml}$ (IQR: 5-10), respectively. Median BMI was $26.12 \mathrm{~kg} / \mathrm{m}^{2}$ (IQR 24-29) with $56(16 \%)$ obese $\left(\mathrm{BMI} \geq 30 \mathrm{~kg} / \mathrm{m}^{2}\right.$ ) patients and 87 (25\%) patients with MetS. At pathological evaluation, advanced PCa and high-grade disease were present in $126(36 \%)$ and 145 (41.5\%) patients, respectively. MetS was significantly associated with advanced PCa (45/87, 51 \% vs 81/262, $31 \%$; $p=0.008)$ and high-grade disease $(47 / 87,54 \%$ vs $98 / 262,37 \% ; p=0.001)$. On multivariable analysis, MetS was an independent predictor of pathological stage $\geq$ pT3a or N1 (OR: 2.227; Cl: 1.273-3.893; $p=0.005)$ and Gleason score $\geq$ $4+3$ (OR: 2.007, Cl: 1.175-3.428; $p=0.011$ ).

Conclusions: We firstly demonstrated in a European radical retropubic prostatectomy cohort study that MetS is associated with an increased risk of high-grade and advanced prostate cancer. Further studies with long term follow-up should evaluate the impact of Mets on PCa survival.
\end{abstract}

Keywords: Prostate, Prostate cancer, Metabolic syndrome, High grade

\footnotetext{
* Correspondence: cosimodenunzio@virgilio.it

'Department of Urology, "Sant'Andrea" Hospital, "La Sapienza" University,

Rome, Italy

Full list of author information is available at the end of the article
} 


\section{Background}

Prostate cancer (PCa) represents the most common non-skin cancer in Western Countries and the second leading cause of cancer death. Notwithstanding the high mortality rate associated with $\mathrm{PCa}$, the only established risk factors are age, race, and family history [1]. Large geographic disparity in $\mathrm{PCa}$ risk suggests that lifestyle factors may contribute to the aetiology of the disease. In fact, Asian men have incidence rates 10- to 15- fold lower than those observed in Western Countries, however $\mathrm{PCa}$ incidence in Eastern Countries and in emigrants has increased rapidly in the last years, suggesting that Westernization may represent an important etiologic factor [2].

Metabolic syndrome (MetS) was firstly described by Reaven in 1988 as complex disorder (Syndrome X), namely a constellation of metabolic abnormalities that increases the risk of coronary artery disease, cardiovascular atherosclerotic diseases and diabetes mellitus type 2 (DMT2) [3]. MetS has become a major public health problem in many Western Countries since its prevalence has been increasing; 35-41\% of adults in the USA are diagnosed with MetS [4]. According to the most widely accepted definition, proposed by the National Cholesterol Education Program's Adult Treatment Panel III (ATPIII), patients with at least 3 of the following factors are considered to have MetS: abdominal obesity (waist circumference $>102 \mathrm{~cm}$ in men or $>88 \mathrm{~cm}$ in women), hypertriglyceridemia (>150 mg/dl), low high density lipoprotein (HDL) cholesterol $(<40 \mathrm{mg} / \mathrm{dl}$ in men and $<50 \mathrm{mg} / \mathrm{dl}$ in women), high blood pressure $(>130 / 85 \mathrm{~mm} \mathrm{Hg})$ and a high fasting blood glucose level (>110 mg/dl) [1, 5].

Recently, increasing evidence supports the hypothesis that different metabolic factors and MetS may be involved in the development and progression of certain types of malignancies [6-8]. A possible association between MetS and PCa was firstly described in 2004 by Laukkanen et al [9] and several subsequent studies in biopsy cohorts have shown conflicting results [1, 10-18].

Aim of our multicentre prospective study was to evaluate the association between MetS, defined according to the ATPIII criteria, and PCa among a consecutive series of men undergoing radical prostatectomy (RP).

\section{Methods}

From January 2012 to June 2015 a consecutive series of men undergoing RP for $\mathrm{PCa}$ at three centres in Italy were enrolled into a prospective database. The study was approved by the Ethics committee of the coordinator centre (Ospedale Sant'Andrea, La Sapienza University of Rome) and then of the Regina Elena National Cancer Institute, Rome, and San Giovanni Bosco Hospital, Turin. All patients signed a dedicated informed consent.
Age and anthropometric parameters including waist circumference and body mass index (BMI) were assessed according to standardized methods and recorded from all patients. Waist circumference was measured, using a standard measurement strip with the patients standing and breathing normally, at the midway between the lowest rib margin and iliac crest [19]. BMI was calculated as weight in kilograms divided by height in meters, squared $\left(\mathrm{kg} / \mathrm{m}^{2}\right)$. Obesity was defined as BMI $\geq 30 \mathrm{~kg} / \mathrm{m}^{2}$. Additionally, resting blood pressure was recorded as the first and fifth Korotkof sounds by auscultation methods [20]. Moreover, fasting (8 hours) blood samples were drawn from all patients during the preoperative assessment evaluation and analysed for blood glucose, HDL cholesterol, triglycerides, total Prostate Specific Antigen (PSA) [1]. Data were used to define a binary variable for the presence or absence of MetS, according to ATPIII [5]. Finally, prostate volume was evaluated before surgery by means of trans-rectal ultrasound.

As per European Association of Urology (EAU) Guidelines [21], surgical treatment was recommended to patients with a life expectancy of at least 10 years and a bioptic diagnosis of $\mathrm{PCa}$, clinically localized or advanced (cT1-T3). Indication to surgery, independently from the presence of MetS, was proposed by a local muldisciplinary uro-oncology team evaluating all the prostate cancer cases diagnosed or referred to each hospital. One dedicated uro-pathologist in each centre performed the histological examinations of the RP specimens.

Pathologic report was standardized [22] according to the histological/architectural thresholds proposed by the World Health Organization (WHO) classification of tumor of the urinary system and male genital organs [23].

\section{Statistical analysis}

Statistical analysis was performed using the Statistical Package for the Social Sciences (SPSS v.21, IBM Corp., Armonk, NY, USA). Evaluation of data distribution using the Kolmogorov-Smirnov test showed a non-normal distribution of the study data set. Differences between groups of patients in medians for quantitative variables and differences in distributions for categorical variables were tested with the Kruskal Wallis one-way analysis of variance and chi-square test, respectively. Using multiple logistic regression with the enter method, the statistical significant variables assessed in the univariate analysis were entered and investigated as predictors of advanced $\mathrm{PCa}$ (pathological Tumor stage $\geq \mathrm{pT} 3 \mathrm{a}$ and/or N1) versus localized PCA, and in a separate model predictors of high grade (Gleason score $\geq 4+3$ ) versus low grade were compared. The logistic regression analysis was carried out using data from patients for whom complete data were available. In order to reduce the risk of redundant variables and subsequent multicollinearity, 
the variables included in the definition of the MetS were excluded from the multivariate analysis. An alpha value of $5 \%$ was considered as threshold for significance. Data are presented as median (Inter quartile range (IQR)) and mean \pm standard deviation (SD). Odds ratios (OR) and $95 \%$ Confidence Intervals $(\mathrm{CI})$ were calculated for the parameters in each model.

\section{Results}

A total of 349 consecutive patients were enrolled (204 at Sant'Andrea Hospital, 78 at Regina Elena Institute and 67 at San Giovanni Bosco Hospital), with a median age and PSA of 66 (IQR: 61-69) years and 7 (IQR: 5-10) ng/ml respectively. Median BMI was 26.12 (IQR: 24-29) with 56 subjects (16\%) being obese. Baseline patients' characteristics are summarized in Table 1. No significant differences $(p>0.05)$ for clinical and pathological characteristics were observed among the three centres (data not shown).

Metabolic Syndrome was diagnosed in 87 patients (25\%) according to ATPIII criteria. Patients with MetS showed higher BMI, waist circumference, fasting glycaemia, trygliceridemia and lower HDL. No statistically significant differences were observed between the MetS-group and the non-MetS-group regarding age $(64.92 \pm 4.87$ years vs $64.05 \pm 6.53$ years; $p=0.473)$, serum PSA levels $(10.80 \pm 16.75 \mathrm{ng} / \mathrm{ml}$ vs $10.41 \pm$ $12.28 \mathrm{ng} / \mathrm{ml} ; p=0.687)$ and prostate volume (53.4 \pm $24.01 \mathrm{ml}$ vs $55.43 \pm 34 \mathrm{ml} ; p=0.661)$. According to the National Comprehensive Cancer Network (NCCN) [24] and the preoperative available data (PSA, bioptic Gleason Score and clinical Stage), patients with $\mathrm{PCa}$ were classified into three categories: Low, Intermediate and High risk. Overall 134 patients (38.6 \%) were diagnosed with a low risk cancer, 117 (33.7\%) with an Intermediate risk and $96(27.7 \%)$ with a High risk. Metabolic syndrome was significantly more prevalent $(p<0.001)$ in the Intermediate (30/117; $25.6 \%)$ and High Risk (36/96;
$37.5 \%)$ population when compared with Low risk (21/134; $15.7 \%)$.

Overall 126 patients (36\%) were found to have a nonorgan confined prostate cancer $(\mathrm{pT} \geq 3 \mathrm{a})$ on pathological RP report (Table 2$)$. Nineteen $(5.4 \%)$ patients presented positive lymph nodes (N1) and all of them had a $\geq$ pT3 PCa. No significant differences were observed between subjects with advanced and localized prostate cancers in terms of waist circumference $(100.34 \pm 9.22 \mathrm{~cm}$ vs 99.3 $\pm 8.13 \mathrm{~cm} ; p=0.503)$, BMI $\left(27.07 \pm 3.79 \mathrm{~kg} / \mathrm{m}^{2}\right.$ vs 26.64 $\left.\pm 3.59 \mathrm{~kg} / \mathrm{m}^{2} ; p=0.149\right)$, glycaemia $(103.87 \pm 21.1 \mathrm{mg} / \mathrm{dl}$ vs $100.83 \pm 19.68 \mathrm{mg} / \mathrm{dl} ; p=0.159)$ and HDL $(50.78 \pm$ $12.34 \mathrm{mg} / \mathrm{dl}$ vs $52.78 \pm 12.34 \mathrm{mg} / \mathrm{dl} ; p=0.925)$. Patients with advanced prostate cancer were older (65.97 \pm 5.97 years vs $63.44 \pm 6.28$ years; $p=<0.001)$ with a higher PSA $(14.54 \pm 17.84 \mathrm{ng} / \mathrm{ml}$ vs $7.81 \pm 4.55 \mathrm{ng} / \mathrm{ml}$, $p<0.001)$ and smaller glands $(51.53 \pm 29.86 \mathrm{ml}$ vs $76 \pm$ $44.05 \mathrm{ml}, p<0.001)$.

High grade PCa (Gleason Score $\geq 4+3$ ) was diagnosed in 145 patients $(41.5 \%)$. Patients with high grade PCa were older $(64.69 \pm 6.28$ years vs $63.43 \pm 6.16$ years; $p<0.001)$, with a higher PSA (13.22 $\pm 18.22 \mathrm{ng} / \mathrm{ml}$ vs $8.79 \pm$ $8.16 \mathrm{ng} / \mathrm{ml} ; p<0.001)$ and smaller glands (53.23 \pm $29.54 \mathrm{ml}$ vs $56.31 \pm 31.57 \mathrm{ml} ; p<0.001$ ) (Table 2).

MetS was significantly associated with advanced PCa (45/87, $51 \%$ vs $81 / 262,31 \% ; p=0.008)$, pathologic nodal involvement $(9 / 87,10 \%$ vs $10 / 262,4 \% ; p=0.028)$ and high grade $\mathrm{PCa}(47 / 87,54 \%$ vs $98 / 262,37 \% ; p=0.001)$. On multivariable analysis serum PSA levels and MetS were independent predictors of pathologic tumor stage $\geq$ $3 \mathrm{a}$ and Gleason score $\geq 4+3$ (Table 3 ).

\section{Discussion}

In our series older patients with higher PSA levels and lower prostate volumes presented an increased risk of advanced and high grade PCa. These data were similar to previous experiences from our centre and from other studies demonstrating a negative correlation between

Table 1 Patient's characteristics according to the presence or absence of Metabolic Syndrome

\begin{tabular}{|c|c|c|c|c|}
\hline & Overall & No MetS & MetS & $p$ \\
\hline Patients (\%) & 349 & $262 / 349(75 \%)$ & $87 / 349(25 \%)$ & \\
\hline Age, years & $64.5 \pm 6.09(66 ; 61 / 69)$ & $64.05 \pm 6.53(65 ; 59 / 69)$ & $64.92 \pm 4.87(65 ; 62 / 68)$ & 0.473 \\
\hline BMI, $\mathrm{kg} / \mathrm{m}^{2}$ & $27.4 \pm 12.77(26.12 ; 24 / 29)$ & $26.56 \pm 3.69(26 ; 24 / 28.4)$ & $28.64 \pm 3.45(28 ; 26.3 / 30.57)$ & $<0.001$ \\
\hline PSA, ng/ml & $9.87 \pm 11.84(7.07 ; 5.08 / 10)$ & $10.41 \pm 12.28(7.11 ; 5.1 / 9.8)$ & $10.80 \pm 16.75(8.18 ; 4.39 / 11.95)$ & 0.687 \\
\hline TRUS Volume, ml & $53.07 \pm 29.59(48 ; 35.1 / 60)$ & $55.43 \pm 34(47.75 ; 36 / 60)$ & $53.4 \pm 24.01(50 ; 37 / 67)$ & 0.661 \\
\hline Waist, $\mathrm{cm}$ & $99.51 \pm 9.85(99 ; 94 / 106)$ & $98.87 \pm 9.45(98 ; 93 / 105)$ & $102.77 \pm 11.3(102.5 ; 96 / 110)$ & 0.009 \\
\hline Glycemia, mg/dl & $101.86 \pm 23.42(96 ; 88 / 108)$ & $98.48 \pm 19.15(94 ; 87 / 104)$ & $113.19 \pm 25.7(111 ; 97 / 111)$ & 0.003 \\
\hline Triglyceridemia, mg/dl & $131.8 \pm 64.4(115 ; 83.7 / 161.2)$ & $126.07 \pm 58(110 ; 83 / 155)$ & $152.11 \pm 78.88(133 ; 87 / 199.5)$ & 0.040 \\
\hline $\mathrm{HDL}, \mathrm{mmol} / \mathrm{l}$ & $51.8 \pm 14.06(50 ; 42 / 59)$ & $52.87 \pm 13.44(51 ; 43 / 60)$ & $47.72 \pm 15.9(45 ; 36.5 / 57)$ & 0.023 \\
\hline Hypertension & $182 / 349(52 \%)$ & $113 / 262(43 \%)$ & 69/87 (79 \%) & $<0.001$ \\
\hline
\end{tabular}

Data are presented as mean \pm SD (median; IQR) 
Table 2 Patient's Characteristics according to pathological Stage and Gleason score

\begin{tabular}{|c|c|c|c|c|c|c|}
\hline & $<$ pT3a & $\geq$ pТ3a & $p$ & $\mathrm{GS}<4+3$ & $G S \geq 4+3$ & $p$ \\
\hline Patients (\%) & $223(64 \%)$ & $126(36 \%)$ & & $204(58.5 \%)$ & $145(41.5 \%)$ & \\
\hline Age, years & $63.44 \pm 6.28(65 ; 59 / 68)$ & $65.97 \pm 5.97(66 ; 62 / 70)$ & $<0.001$ & $63.43 \pm 6.16(64 ; 59 / 68)$ & $64.69 \pm 6.28(66 ; 61 / 69)$ & 0.158 \\
\hline TRUS Volume, ml & $76 \pm 44.05(60 ; 44 / 96)$ & $51.53 \pm 29.86(47 ; 33.6 / 60)$ & $<0.001$ & $56.31 \pm 31.57(50 ; 38 / 62.5)$ & $53.23 \pm 29.54(49.5 ; 35.5 / 57.9)$ & 0.018 \\
\hline Waist, cm & $99.30 \pm 8.13(98.87 ; 96 / 102.77)$ & $100.34 \pm 9.22(98.87 ; 96 / 102.77)$ & 0.503 & $99.21 \pm 8.88(99 ; 94 / 105)$ & $98.63 \pm 10.89(97 ; 92 / 103)$ & 0.549 \\
\hline $\mathrm{BMl}, \mathrm{kg} / \mathrm{m}^{2}$ & $26.64 \pm 3.59(26.98 ; 24 / 28.65)$ & $27.07 \pm 3.79(26.4 ; 24 / 30)$ & 0.149 & $26.51 \pm 3.54(26.98 ; 24 / 28.4)$ & $27.10 \pm 3.8(26.52 ; 24 / 29.2)$ & 0.131 \\
\hline PSA, ng/ml & $7.81 \pm 4.55(6.8 ; 4.79 / 9.43)$ & $14.54 \pm 17.84(8.28 ; 6.23 / 14.09)$ & $<0.001$ & $8.79 \pm 8.16(6.6 ; 4.96 / 9.42)$ & $13.22 \pm 18.22(8.7 ; 6.15 / 11.7)$ & $<0.001$ \\
\hline Trygliceridemia, mg/dl & $130.65 \pm 63.4(105 ; 83 / 163)$ & $136.23 \pm 65.86(122 ; 86 / 161.5)$ & 0.648 & $130.92 \pm 50.74(126 ; 94 / 152)$ & $135.25 \pm 60(126 ; 94 / 152)$ & 0.552 \\
\hline Glycaemia, mg/dl & $100.83 \pm 19.68(98 ; 91 / 104)$ & $103.87 \pm 21.1(98 ; 92 / 111)$ & 0.159 & $100.19 \pm 20.85(95 ; 88 / 107)$ & $103.84 \pm 23.15(96 ; 88 / 108)$ & 0.153 \\
\hline $\mathrm{HDL}, \mathrm{mg} / \mathrm{dl}$ & $52.14 \pm 11.73(52 ; 45 / 56)$ & $50.78 \pm 12.34(52 ; 44 / 55.25)$ & 0.925 & $52.1 \pm 11.14(52 ; 46 / 55)$ & $51.03 \pm 12.99(52 ; 43 / 56.75)$ & 0.213 \\
\hline Hypertension & $102 / 223(47 \%)$ & $74 / 126(59 \%)$ & 0.037 & $88 / 204(43 \%)$ & $91 / 145(63 \%)$ & 0.001 \\
\hline
\end{tabular}

Kruskal Wallis test for continuous variables, chi square test for categorical variables. GS = Gleason score 
Table 3 Univariable and multivariable analysis for predicting advanced pathological stage and high pathological grade PCa

\begin{tabular}{|c|c|c|c|c|c|c|c|c|}
\hline & \multicolumn{4}{|c|}{ Advanced pathological stage ( $\geq$ pT3a or N1) } & \multicolumn{4}{|c|}{ High pathological Gleason Score $(\geq 4+3)$} \\
\hline & Crude OR & p & Multivariable & $p$ & Crude OR & p & Multivariable & $p$ \\
\hline Age, years & OR: 1.051 (Cl: 1.010-1.094) & 0.014 & OR: 1.044 (Cl: 0.997-1.094) & 0.006 & OR: 1.021 (Cl: 0.984-1.060) & 0.268 & OR: 1.001 (Cl: 0.961-1.044) & 0.949 \\
\hline TRUS Volume, ml & OR: 0.994 (Cl: 0.987-1.002) & 0.155 & OR: 0.993 (Cl: 0.983-1.003) & 0.173 & OR: 0.997 (Cl: 0.989-1.004) & 0.356 & OR: 0.998 (Cl: 0.989-1.006) & 0.594 \\
\hline PSA, ng/ml & OR: 1.068 (Cl: 1.033-1.134) & 0.001 & OR: 1.121 (Cl: 1.060-1.185) & 0.001 & OR: 1.038 (Cl: 1.012-1.065) & 0.004 & OR: 1.064 (Cl: 1.024-1.106) & 0.002 \\
\hline $\mathrm{BMI}, \mathrm{kg} / \mathrm{m}^{2}$ & OR: 1.016 (Cl: 0.945-1.092) & 0.673 & & & OR: 1.027 (Cl: 0.957-1.102) & 0.459 & & \\
\hline MetS & OR: 2.439 (Cl: 1.492-3.987) & 0.004 & OR: 2.697 (Cl: 1.481-4.913) & 0.001 & OR: 1.886 (Cl: 1.164-3.054) & 0.010 & OR: 1.880 (Cl: 1.066-3.316) & 0.029 \\
\hline Waist, cm & OR: 1.016 (Cl: 0.990-1.043) & 0.218 & & & OR: 1.009 (Cl: 0.984-1.034) & 0.494 & & \\
\hline Glycaemia, mg/dl & OR: 1.007 (Cl: 0.996-1.018) & 0.203 & & & OR: 1.007 (Cl: 0.997-1.018) & 0.181 & & \\
\hline Trygliceridemia, mg/dl & OR: 1.001 (Cl: 0.997-1.005) & 0.565 & & & OR: 1.002 (Cl: 0.998-1.005) & 0.423 & & \\
\hline $\mathrm{HDL}, \mathrm{mg} / \mathrm{dl}$ & OR: 1.001 (Cl: 0.983-1.019) & 0.947 & & & OR: 0.992 (Cl: 0.974-1.010) & 0.374 & & \\
\hline Hypertension & OR: 1.621 (Cl: 0.987-2.662) & 0.056 & & & OR: 2.180 (Cl: 1.330-3.575) & 0.002 & & \\
\hline
\end{tabular}

OR= Odds Ratio 
prostate volume and $\mathrm{PCa}$ extent and aggressiveness [1, 25-29]. Specifically, Freedland et al reported a significantly higher incidence of advanced disease in men with small prostates [25]; Kassouf et al described that more poorly differentiated tumors were found at RP in subjects with small prostate volumes than in those with larger glands [28]. The biological mechanism accountable for the inverse association between prostate volume and cancer aggressiveness remains to be explicated. Since more PSA diffuses into the circulation from cancerous cells than from benign prostatic tissues, it is theorized that men with higher PSA density may have an increased risk of harbouring high-grade/advanced-stage PCa [30].

In the present study we observed that MetS is a common condition $(87 / 349,25 \%)$ among patients undergoing RP and is more prevalent than obesity (56/349, $16 \%)$. In a previous experience, we reported that MetS was even more prevalent (44\%) in patients at risk of PCa for an elevated PSA or an abnormal digital rectal examination and we also showed that MetS was associated with an increased risk (OR: 3.8; $95 \%$ CI 1.33-10.9) of Gleason score $\geq 7$ in patients with $\mathrm{PCa}$ at biopsy [1]. Our results have been later confirmed by Morote et al [14] (OR 1.75; $95 \%$ CI 1.26-2.41) and Kayaly et al [12] (OR 1.8; 95 \% CI 0.87-3.74) on similar bioptic studies. Notwithstanding all these studies, the association between MetS and PCa is still controversial. Most of the studies conducted on the European population have demonstrated a positive association between MetS and PCa incidence, aggressiveness and outcomes $[9,11,13]$. Similar cohort studies performed on Americans revealed null [17] or inverse [16] associations. Making a comparison between our series and the USA one may be misleading because of heterogeneity in age, race and BMI distribution. Our cohort is entirely Caucasian with neither Africans nor Hispanics and, although in line with the average Italian population, it is less obese $(16 \%$ vs $34 \%$ ) and older (median age 66 vs 62 years) when compared to other experience from USA series $[1,6,31]$. In 2013, Xiang et al conducted a meta-analysis confirming a weak association between MetS and PCa risk, although men with MetS appeared more likely to have a grater risk of biochemical progression after RP and a higher cancer-specific mortality [18]. Bhindi and colleagues recently highlighted that no individual MetS component is independently associated with PCa outcomes, however a correlation between the number of MetS components and the odds of $\mathrm{PCa}$ diagnosis exists, with a biologic gradient present [10]. Finally, data from a recent study based on the REDUCE (Reduction by Dutasteride of Prostate Cancer Events) population confirmed that having two or three to four MetS features was associated with increased risk of high-grade PCa (OR 1.35 and 1.94 respectively) [15].
One of the most important limitations and criticisms of the available evidence on the relationship between $\mathrm{PCa}$ and MetS is the lack of confirmatory studies on RP as most of the studies were performed on prostate biopsy cohorts where a significant percentage of patients with a negative biopsy unfortunately harbour a PCa. In order to overcome these limitations, we designed the first prospective multicentre study conducted on a consecutive series of patients undergoing RP using a standardized definition of MetS as the one proposed by ATPIII [5]. We observed that MetS is significantly associated with advanced PCa: patients with MetS presented a 2-fold increased risk of advanced stage and high-grade cancer. Our results are also supported by the retrospective single centre study presented by Kheterpal E et al [32], although data are not comparable since the author defined the presence of MetS using the criteria proposed by the International Diabetes Federation.

The biological mechanisms explaining these findings remain unknown. MetS features are known to accompany a pro-inflammatory state (elevated levels of C-reactive protein, TNF- $\alpha$, interleukin $8,6,1 \beta)$, which in turn has been related to prostate cancer risk [33-36]. Moreover, men with MetS are commonly diagnosed with hyperinsulinemia that has been associated with increased risk of PCa death. Finally, elevated circulating levels of IGF-1, leptin and adiponectin, commonly encountered in MetS patients, have all been associated with prostate cancer risk. However, current knowledge probably represents a minimal part of the biological mechanisms behind these associations and forthcoming studies are awaited [6].

We must acknowledge some limitations of our study. This is a multicentre study of patients with prostate cancer undergoing radical retropubic prostatectomy with a limited population of Caucasian men with no Africans or Hispanics; so far, our results cannot be extended to all patients with prostate cancer. Furthermore, a comprehensive evaluation of the association between MetS and PCa should include data on the different therapeutic options available for the management of T1T3 PCa patients. However, although a trial investigating the impact of MetS in patients treated with External Beam Radio Therapy is ongoing in one of our centres and data will be soon available, the current study did not evaluate other possible treatment options. Considering the conflicting results reported by different authors when investigating the association between MetS and $\mathrm{PCa}$ in non-European populations, confirmatory findings from multicentre studies based on larger cohorts of patients of different ethnicities, receiving different treatment, are warranted.

Another limitation derives from the lack of information in the current study regarding physical activity or diet, which are associated with MetS, risk of $\mathrm{PCa}$ and 
potentially cancer grade at diagnosis [6]. Finally the lack of long-term oncologic outcomes, including at least biochemical recurrence free and metastasis free survivals does not allow supporting MetS as an independent predictor of poor oncologic outcomes. However this study is ongoing and results will be available in the near future.

Notwithstanding all these limitations, our study is the first prospective study evaluating patients treated with RP using the ATPIII criteria to define the presence of MetS. Our results, if confirmed, could open new issues in the management of patients with $\mathrm{PCa}$ and MetS as well as new studies investigating the role of physical activity, diet and medical treatment for MetS on PCa development and progression.

\section{Conclusions}

In our multi centre study, we firstly observed that MetS is associated with an increased risk of high-grade pathological Gleason score and advanced pathological stage in patients with PCa treated with RP. Even though the molecular pathways are yet to be understood, it is assumable that metabolic factors should be considered as possible drivers of $\mathrm{PCa}$ differentiation and progression.

\section{Abbreviations}

ATPIII, National Cholesterol Education Program's Adult Treatment Panel III; $\mathrm{BMI}$, body mass index; Cl, confidence interval; DMT2, diabetes mellitus type 2; EAU, European Association of Urology; HDL, high density lipoprotein; IQR, Inter quartile range; MetS, metabolic syndrome; OR, Odds ratio; $\mathrm{PCa}$, prostate cancer; PSA, Prostate Specific Antigen; REDUCE, Reduction by Dutasteride of Prostate Cancer Events trial; RP, radical prostatectomy; SD, standard deviation; TNF, Tumor Necrosis Factor; WHO, World Health Organization

\section{Acknowledgments}

None.

\section{Funding}

No funding to declare.

\section{Availability of data and materials}

The dataset supporting the conclusions of this article is available in the Open Science Framework website at https://osf.io/7yavx/.

\section{Authors' contribution}

All authors have red and approved the manuscript. CD was involved in the conception and design of the study and in statistical analysis; $A B$ and RM in data acquisition; $C D, G S, A B$ and $D C$ were involved in the interpretation of results. $A B$ and $C D$ in drafting the manuscript. $C D, G M, M G$ and $A T$ revised the manuscript critically. All authors red and approved the final manuscript.

\section{Competing interests}

The authors declare that they have no competing interests.

\section{Consent for publication}

Not applicable.

\section{Ethics approval and consent to participate}

The study was approved by the Ethics committee of the coordinator centre (Ospedale Sant'Andrea, La Sapienza University of Rome) and then of the Regina Elena National Cancer Institute, Rome, and San Giovanni Bosco Hospital, Turin. All patients signed a dedicated informed consent.

\section{Author details}

"Department of Urology, "Sant'Andrea" Hospital, "La Sapienza" University, Rome, Italy. "Department of Urology, "Regina Elena" National Cancer Institute Rome, Italy. ${ }^{3}$ Department of Urology, "San Giovanni Bosco" Hospital, Turin, Italy.

Received: 18 December 2015 Accepted: 24 June 2016

Published online: 07 July 2016

\section{References}

1. De Nunzio C, Freedland SJ, Miano R, Trucchi A, Cantiani A, Carluccini A et al. Metabolic syndrome is associated with high grade gleason score when prostate cancer is diagnosed on biopsy. Prostate. 2011;71:1492-8. doi:10.1002/pros.21364.

2. Esposito K, Chiodini P, Capuano A, Bellastella G, Maiorino MI, Parretta E, et al. Effect of metabolic syndrome and its components on prostate cancer risk: meta-analysis. J Endocrinol Invest. 2013;36:132-9. doi:10.1007/BF03346748

3. Reaven GM. Banting lecture 1988. Role of insulin resistance in human disease. Diabetes. 1988;37:1595-607.

4. Ozbek E, Otunctemur A, Dursun M, Sahin S, Koklu I, Erkoc M, et al. The Metabolic Syndrome is Associated with More Aggressive Prostate Cancer. Asian Pac J Cancer Prev. 2014;15:4029-32.

5. Third Report of the National Cholesterol Education Program (NCEP) Expert Panel on Detection, Evaluation, and Treatment of High Blood Cholesterol in Adults (Adult Treatment Panel III) final report. Circulation 2002:106:3143-421.

6. De Nunzio C, Presicce F, Lombardo R, Cancrini F, Petta S, Trucchi A, et al. Physical activity as a risk factor for prostate cancer diagnosis: a prospective biopsy cohort analysis. BJU Int 2015. doi:10.1111/bju.13157.

7. De Nunzio C, Albisinni S, Freedland SJ, Miano L, Cindolo L, Finazzi Agrò E, et al. Abdominal obesity as risk factor for prostate cancer diagnosis and high grade disease: a prospective multicentre Italian cohort study. Urol Oncol. 2013:31:997-1002 doi:10.1016/j.urolonc 2011.08.007.

8. De Nunzio C, Truscelli G, Trucchi A, Petta S, Tubaro M, Gacci M, et al. Metabolic abnormalities linked to an increased cardiovascular risk are associated with high-grade prostate cancer: a single biopsy cohort analysis. Prostate Cancer Prostatic Dis 2015. doi:10.1038/pcan.2015.45.

9. Laukkanen JA, Laaksonen DE, Niskanen L, Pukkala E, Hakkarainen A, Salonen JT. Metabolic syndrome and the risk of prostate cancer in Finnish men: a population-based study. Cancer Epidemiol Biomarkers Prev. 2004;13:1646-50.

10. Bhindi B, Locke J, Alibhai SMH, Kulkarni GS, Margel DS, Hamilton RJ, et al. Dissecting the association between metabolic syndrome and prostate cancer risk: analysis of a large clinical cohort. Eur Urol. 2014;67:64-70. doi:10.1016/j.eururo.2014.01.040.

11. Grundmark B, Garmo H, Loda M, Busch C, Holmberg L, Zethelius B. The metabolic syndrome and the risk of prostate cancer under competing risks of death from other causes. Cancer Epidemiol Biomarkers Prev. 2010:19:2088-96. doi:10.1158/1055-9965.EPI-10-0112.

12. Kayali M, Balci M, Aslan Y, Bilgin O, Guzel O, Tuncel A, et al. The relationship between prostate cancer and presence of metabolic syndrome and ate-onset hypogonadism. Urology. 2014;84:1448-52. doi:10.1016/j.urology.2014.07.015.

13. Lund Håheim L, Wisløff TF, Holme I, Nafstad P. Metabolic syndrome predicts prostate cancer in a cohort of middle-aged Norwegian men followed for 27 years. Am J Epidemiol. 2006;164:769-74. doi:10.1093/aje/kwj284.

14. Morote J, Ropero J, Planas J, Bastarós JM, Delgado G, Placer J, et al. Metabolic syndrome increases the risk of aggressive prostate cancer detection. BJU Int. 2013;111:1031-6. doi:10.1111/j.1464-410X.2012.11406.X.

15. Sourbeer KN, Howard LE, Andriole GL, Moreira DM, Castro-Santamaria R, Freedland SJ, et al. Metabolic syndrome-like components and prostate cancer risk: results from the Reduction by Dutasteride of Prostate Cancer Events (REDUCE) study. BJU Int. 2015;115:736-43. doi:10.1111/bju.12843.

16. Tande AJ, Platz EA, Folsom AR. The metabolic syndrome is associated with reduced risk of prostate cancer. Am J Epidemiol. 2006;164:1094-102. doi:10.1093/aje/kwj320

17. Wallner LP, Morgenstern H, McGree ME, Jacobson DJ, St Sauver JL, Jacobsen SJ, et al. The effects of metabolic conditions on prostate cancer incidence over 15 years of follow-up: results from the Olmsted County Study. BJU Int 2011;107:929-35. doi:10.1111/j.1464-410X.2010.09703.X.

18. Xiang $Y$, Xiong $H$, Cui Z, Jiang $S$, Xia Q, Zhao $Y$, et al. The association between metabolic syndrome and the risk of prostate cancer, high-grade 
prostate cancer, advanced prostate cancer, prostate cancer-specific mortality and biochemical recurrence. J Exp Clin Cancer Res. 2013;32:9. doi:10.1186/1756-9966-32-9.

19. Abdeen Z, Jildeh C, Dkeideek S, Qasrawi R, Ghannam I, Al Sabbah H. Overweight and obesity among Palestinian adults: analyses of the anthropometric data from the first national health and nutrition survey (1999-2000). J Obes. 2012;2012:213547. doi:10.1155/2012/213547.

20. Frese EM, Fick A, Sadowsky HS. Blood pressure measurement guidelines for physical therapists. Cardiopulm Phys Ther J. 2011;22:5-12.

21. Heidenreich A, Bastian PJ, Bellmunt J, Bolla M, Joniau S, van der Kwast T, et al. EAU guidelines on prostate cancer. part 1: screening, diagnosis, and local treatment with curative intent-update 2013. Eur Urol. 2014;65:124-37. doi:10.1016/j.eururo.2013.09.046.

22. Epstein JI, Srigley J, Grignon D, Humphrey P. Recommendations for the reporting of prostate carcinoma. Hum Pathol. 2007;38:1305-9. doi:10.1016/j.humpath.2007.05.015.

23. Eble JN, Sauter G, Epstein JI, Sesterhenn IA. Pathology and Genetics of Tumours of the Urinary System and Male Genital Organs. IARC Press 2004:1-353. doi:10.1016/j.urology.2004.09.048.

24. Rodrigues G, Warde P, Pickles T, Crook J, Brundage M, Souhami L, et al. Pre-treatment risk stratification of prostate cancer patients: A critical review. Can Urol Assoc J. 2012;6:121-7. doi:10.5489/cuaj.11085.

25. Freedland SJ, Isaacs WB, Platz EA, Terris MK, Aronson WJ, Amling CL, et al. Prostate size and risk of high-grade, advanced prostate cancer and biochemical progression after radical prostatectomy: a search database study. J Clin Oncol. 2005;23:7546-54. doi:10.1200/JCO.2005.05.025.

26. Freedland SJ, Wieder JA, Jack GS, Dorey F, DeKernion JB, Aronson WJ. Improved risk stratification for biochemical recurrence after radical prostatectomy using a novel risk group system based on prostate specific antigen density and biopsy Gleason score. J Urol. 2002;168:110-5. doi:10.1097/00005392-200207000-00025.

27. Oh JJ, Hong SK, Lee JK, Lee BK, Lee S, Kwon OS, et al. Prostate-specific antigen vs prostate-specific antigen density as a predictor of upgrading in men diagnosed with Gleason 6 prostate cancer by contemporary multicore prostate biopsy. BJU Int. 2012;110:494-9. doi:10.1111/j.1464-410X.2012.11182.x.

28. Kassouf W, Nakanishi H, Ochiai A, Babaian KN, Troncoso P, Babaian RJ. Effect of prostate volume on tumor grade in patients undergoing radical prostatectomy in the era of extended prostatic biopsies. J Urol. 2007:178:111-4. doi:10.1016/.juro.2007.03.013.

29. Corcoran NM, Casey RG, Hong MKH, Pedersen J, Connolly S, Peters J, et al. The ability of prostate-specific antigen (PSA) density to predict an upgrade in Gleason score between initial prostate biopsy and prostatectomy diminishes with increasing tumour grade due to reduced PSA secretion per unit tumour volume. BJU Int. 2012;110:36-42. doi:10.1111/j.1464-410X.2011.10681.X.

30. Kundu SD, Roehl KA, Yu X, Antenor JA V, Suarez BK, Catalona WJ. Prostate specific antigen density correlates with features of prostate cancer aggressiveness. J Urol. 2007;177:505-9. doi:10.1016/j.juro.2006.09.039.

31. Beebe-Dimmer JL, Nock NL, Neslund-Dudas C, Rundle A, Bock CH, Tang D, et al. Racial differences in risk of prostate cancer associated with metabolic syndrome. Urology. 2009;74:185-90. doi:10.1016/j.urology.2009.03.013.

32. Kheterpal E, Sammon JD, Diaz M, Bhandari A, Trinh Q-D, Pokala N, et al. Effect of metabolic syndrome on pathologic features of prostate cancer. Urol Oncol. 2013;31:1054-9. doi:10.1016/j.urolonc.2011.12.012.

33. Sfanos KS, De Marzo AM. Prostate cancer and inflammation: the evidence. Histopathology. 2012;60:199-215. doi:10.1111/j.1365-2559.2011.04033.x.

34. Powell IJ, Bollig-Fischer A. Minireview: the molecular and genomic basis for prostate cancer health disparities. Mol Endocrinol. 2013;27:879-91. doi:10.1210/me.2013-1039.

35. De Marzo AM, Platz EA, Sutcliffe S, Xu J, Grönberg H, Drake CG, et al. Inflammation in prostate carcinogenesis. Nat Rev Cancer. 2007;7:256-69. doi:10.1038/nrc2090.

36. De Nunzio C, Aronson W, Freedland SJ, Giovannucci E, Parsons JK. The correlation between metabolic syndrome and prostatic diseases. Eur Urol. 2012;61:560-70. doi:10.1016/j.eururo.2011.11.013.

\section{Submit your next manuscript to BioMed Central and we will help you at every step:}

- We accept pre-submission inquiries

- Our selector tool helps you to find the most relevant journal

- We provide round the clock customer support

- Convenient online submission

- Thorough peer review

- Inclusion in PubMed and all major indexing services

- Maximum visibility for your research

Submit your manuscript at www.biomedcentral.com/submit
Biomed Central 